\title{
O Estado Concorrencial e as Mudanças na Natureza do Trabalho no Setor Público
}

\author{
Antonio Moreira de Carvalho Neto
}

\section{ResUMO}

O Estado Keynesiano entrou em crise diante da globalização econômica. Observa-se uma mudança de função do Estado na direção do Estado Concorrencial, que aceita integralmente a lógica das duras condições da concorrência no mercado mundial, envidando esforços para aumentar a competitividade de grupos de capital espacialmente definidos. A reestruturação produtiva da economia veio acompanhada de políticas privatizantes e de abertura de mercado. Isso levou os Estados Concorrenciais a disputas para atrair investimentos, no tempo em que incentivam a flexibilização do contrato de trabalho e variadas práticas de subcontratação, como formas de diminuir os custos do trabalho. O presente artigo analisa as novas formas de organização do setor de prestação de serviços públicos de telecomunicações. Baseando-se em pesquisa realizada em duas das quatro maiores empresas do setor no Brasil, os resultados encontrados indicam a adoção de variadas formas de subcontratação de serviços, algumas delas de inusitada profundidade e abrangência, trazendo mudanças na gestão do setor, na natureza e nas relações de trabalho.

Palavras-chaves: Estado concorrencial, terceirização, quarteirização, relações de trabalho, mudança nos serviços públicos.

\begin{abstract}
The economic globalization brought a shift from Keynesian State to the competitive State, which accepts a fierce international competition, enforcing national economic groups. Economic restructuring, together with the opening of markets forced these States to cut off labour costs, in order to attract foreign investment. This article analyses the contracting out system in two of the four biggest telecommunications public enterprises. The research points to the adoption of several kinds of contracting out practices, some of them rather unusual. This situation brought changes in both the management and the labour relations.
\end{abstract}

Key words: competitive State, contracting out, contracting out the contracting out, labour relations, public services change.

\section{INTRODUÇÃO}

O presente trabalho busca analisar as novas formas de organização do setor de prestação de serviços públicos de telecomunicações no Brasil, que passa por processo de desregulamentação, refletindo as mudanças no papel do Estado que estão ocorrendo internacionalmente. Pretende-se examinar também as mudanças na natureza do trabalho decorrentes dessas novas formas de organização.

Na segunda seção discute-se a passagem do Welfare State, o "Estado-Providência", que intervinha mais diretamente na economia e provia o bem-estar dos cidadãos, para o Estado Concorrencial, que passa a intervir na economia de maneira mais indireta e com caráter regulador destinado a estimular a competitividade para enfrentar as duras condições da concorrência internacional, num mundo cada vez mais globalizado. Na terceira seção analisam-se as mudanças provocadas na natureza do trabalho pelas novas formas organizacionais nas empresas e no setor público nesse quadro de novo papel do Estado. 
Na quarta seção são tecidas as considerações metodológicas que nortearam a pesquisa feita nos Estados de Minas Gerais e do Rio de Janeiro. Na quinta e sexta seções são analisados os resultados da pesquisa e apresentadas as conclusões.

\section{Do Welfare State ao Estado Concorrencial}

Estado e mercado sempre estiveram em mútua interação no mundo moderno. A relativa influência do Estado ou do mercado muda no tempo e sob diferentes circunstâncias. Interesses e decisões políticas influenciam tanto as atividades econômicas quanto os seus custos e benefícios. Por outro lado, o mercado e as forças econômicas afetam a ditribuição do poder e da riqueza entre os Estados e os outros atores políticos (Gilpin, 1987).

O Estado sempre adotou medidas para proteger a sociedade e/ou seus próprios interesses no jogo de poder nacional e internacional, seja contra as falhas de mercado, seja até desorganizando a vida industrial. Para isso utiliza de mais ou menos regulamentação, conforme os interesses estatais de acordo com o estágio de desenvolvimento de determinado ciclo do capitalismo.

Arrighi (1996), estudando os ciclos hegemônicos de acumulação capitalista desde o século XV, conclui que nos últimos 500 anos a expansão capitalista se deveu em grande parte à capacidade do Estado, que se constituiu em potência hegemônica durante determinado ciclo, em promover, organizar e regular uma nova fase expansionista. Assim foi durante os cem anos - inéditos - de Pax Britannica na Europa (do fim das Guerras Napoleônicas em 1815 até a I Guerra Mundial em 1914), quando o Reino Unido controlava o mercado mundial pela supremacia naval e pela sua estrutura de entreposto comercial. Assim tem sido durante a hegemonia norte-americana, de caráter mais intervencionista e regulador que a britânica (Arrighi, 1996), devido à dependência da economia mundial em relação ao dólar. Aqui se trata, portanto, de intervenção estatal em nível macro na economia política internacional, que se desdobra para o nível local de cada país.

Durante os anos 50 e 60, de grande expansão econômica sob o modelo fordista de regulação (para se utilizar o termo da escola francesa de mesmo nome), implantado no pós-guerra pelos EUA no Japão e na Europa, realizou-se o círculo virtuoso: investimento - expansão da produção - pleno emprego - aumento da produtividade - aumento real de salários - consumo de massa - ganhos de escala - investimentos. Na Europa e no Japão houve acentuada intervenção estatal no tocante à política industrial e de investimentos. Em praticamente todos os países mais desenvolvidos houve variados graus de regulação de políticas salariais e a instituição de políticas de proteção social, sistema que ficou conhecido como Welfare State (Lipietz,1991).

O sistema fordista de regulação começa a dar sinais de crise de mercado, social e monetária a partir do final dos anos 60. A saturação do mercado de bens duráveis, provocando a desaceleração na economia (redução no nível de investimento), aliada à queda na produtividade (afetada pela queda no investimento tecnológico e pela maior resistência dos trabalhadores às tarefas repetitivas e à rígida disciplina fabril) provocou um quadro de esgotamento do padrão industrial vigente (Teixeira,1994; Lipietz,1991). O rápido crescimento industrial dessas duas décadas esteve associado a crescente endividamento por parte das famílias, das empresas e do governo. Com o desaquecimento da economia, esse endividamento se tornou cumulativo, elevando o custo financeiro das empresas, induzindo o repasse de preços nos setores oligopolizados, formadores de preços em escala internacional. O setor público perdia receitas (impostos) e aumentava as despesas (custos financeiros), agravando a pressão inflacionária (Teixeira, 1994).

A crise da economia americana agravou-se no início dos anos 70 . Os déficits fiscal e no balanço de pagamentos minaram a confiança no dólar, provocando intensa especulação no mercado financeiro internacional. Bilhões de dólares foram transferidos para o mercado de eurodólares. A perda de competitividade para as indústrias japonesas e européias, das quais o governo americano tinha tolerado um elevado grau de protecionismo comercial aliado a agressivas políticas exportadoras, em nome da construção de uma próspera barreira econômica (e ideológica) em face do bloco socialista, só veio agravar esse quadro (Kolko, 1988; Gilpin, 1987; Kurtzman, 1994).

O governo americano, como condutor da potência hegemônica que, em última análise, é quem deveria 
patrocinar a estabilidade internacional, ordenando, regulando e coordenando os interesses dos demais países em competição, segundo a teoria da estabilidade hegemônica (Gilpin, 1987), assim o fez até 1971, quando, para responder ao declínio de sua economia, rompeu unilateralmente o sistema de paridades fixas que havia atrelado todas as moedas do mundo ao dólar, instituindo um sistema de taxas de câmbio flutuantes (Teixeira, 1994; Kurtzman, 1994).

Essa crise do padrão monetário internacional (o dólar) instabilizou a economia mundial na década de 70, impondo ajustes macroeconômicos a todos os países, situação agravada pelo primeiro choque do petróleo. Políticas antinflacionárias recessivas foram adotadas em todas as economias centrais, com retração da demanda e do nível de investimento e emprego (Arrighi, 1996; Tavares e Fiori, 1993).

A partir de meados dos anos 70, à crise da hegemonia econômica dos EUA soma-se a crise político-militar advinda da derrota no Vietnã e intensificada pelos desafios iraniano, nicaraguense e da OPEP. O governo Reagan responde com a intensificação da corrida armamentista contra a URSS, que Hobsbawm (1995) chama de Segunda Guerra Fria. Japão e Alemanha, basicamente, financiam o déficit americano, por razões tanto políticas e estratégicas quanto comerciais (Gilpin, 1987; Arrighi, 1996), já que se beneficiavam da tolerância americana ao seu protecionismo comercial.

A capacidade dos EUA em demonstrar que o seu papel hegemônico era do interesse das outras potências foi abalada com a crise de liderança moral e intelectual, para utilizar um conceito gramsciano de poder. Os EUA transformaram-se de maior nação credora em maior país devedor do planeta. O governo Reagan intervém na economia internacional, numa política de "hegemonia predatória" (Gilpin, 1987, p.90), promovendo a recentralização do poder de compra nos EUA, reduzindo a oferta monetária, aumentando a taxa de juros para atrair capital e desregulamentando o sistema financeiro americano. O resultado foi o acelerado crescimento do mercado financeiro internacional e a menor capacidade de os governos nacionais controlarem ou mesmo estabelecerem políticas monetárias próprias (Kolko, 1988; Teixeira, 1994; Hobsbawm, 1995; Arrighi, 1996). Houve uma febre de investimentos não produtivos em fusões e take overs, muitos deles mediante operações de alto risco, montadas por agentes especializados (raiders) em desmembrar empresas para vender partes em enormes compras especulativas de ações até 1987, quando ocorre o crack da bolsa de New York, que força intervenção do governo americano (Kolko, 1988).

Esse novo contexto de crise da hegemonia dos EUA impulsiona as empresas americanas no sentido de maior competição no mercado externo; a crescente globalização da economia que se segue traz o acirramento da competição internacional e da procura pelas empresas, especialmente transnacionais, de novos mercados em todo o planeta (Porter,1993).

Os setores de ponta na competição internacional passam por reestruturação produtiva que reúne elementos de racionalização técnica e organizacional, puxando o restante da economia. A racionalização técnica tem substituído a mão-de-obra por agregados científicos com alto investimento de capital, como a "mecatrônica", mudança da base metal-mecânica para eletrônica (Carvalho Neto, 1995). A racionalização organizacional tem sido feita com o enxugamento drástico das estruturas empresariais fordistas e com a divisão destas em unidades de produção menores e mais independentes. A focalização no negócio da empresa, passando a subcontratar os serviços que não são atividade-fim, generalizou-se (Kolko, 1988). Os processos produtivos têm sido redesenhados, com o advento da automação flexível (Lipietz, 1991; Arrighi, 1996).

As disputas intra e entre os novos blocos econômicos fazem aumentar a pressão por maior abertura comercial (Porter, 1993). Essa intensificação nas pressões para abertura das economias nacionais implica políticas de privatização de empresas estatais e desregulamentação ou flexibilização de monopólios estatais.

É na esteira dessa crise que ganha força a concepção que defende o Estado Liberal, retraído, intervindo na economia de maneira residual, somente para resolver os conflitos e falhas de mercado, assegurando o seu funcionamento eficiente. Freqüentemente intitulada "neoliberal", esta corrente passa a se contrapor à concepção que defende o Estado Keynesiano, mais intervencionista, como promotor e empreendedor do desenvolvimento econômico e social, o Welfare State (Kolko, 1988; Tauile et al, 1994).

As políticas privatizantes, que desempenham papel central no projeto de economia de mercado (Altvater, 
1995), com seus variados graus de intensidade, seja vendendo parte ou o total de ações do governo em uma empresa estatal, seja desregulamentando ou flexibilizando um setor de monopólio estatal para permitir a concorrência com a iniciativa privada, ou subcontratando serviços de empresas privadas (contracting out), entraram em pauta definitivamente a partir dos anos 80 (Savas, 1987). Especialmente a partir do advento do governo liberal da ministra Thatcher no Reino Unido, que representou a experiência mais radical neste sentido no âmbito dos países mais desenvolvidos, impulsionaram-se as pressões para que fossem adotadas políticas semelhantes no restante do mundo (Carvalho Neto, 1994).

Pode-se observar, pelo exposto acima, que o atual estágio da economia é muito mais decorrência de um conjunto de decisões políticas por parte dos Estados Nacionais que detêm o poder econômico mundial do que o simples resultado de decisões microeconômicas de empresários inovadores (Altvater, 1995).

Viu-se também como o Welfare State e o Estado Keynesiano intervencionista, essencialmente um Estado Nacional, entram em crise diante da globalização econômica, aparecendo como obstáculo à circulação de bens, capitais e serviços. Ainda assim, as sociedades modernas são organizadas em Estados Nacionais, e mesmo o discurso liberal do Estado-mínimo supõe sociedades claramente delimitadas para fora.

O que estaria ocorrendo, segundo Altvater (1995), seria a mudança de função do Estado na direção do Estado Concorrencial Nacional, que aceita integralmente a lógica das duras condições da concorrência no mercado mundial, envidando esforços politicamente legitimados para fortalecer a competitividade e proteger grupos de capital espacialmente definidos. $\mathrm{O}$ surgimento de um macrorregionalismo de comunidades concorrenciais, representadas pelos blocos econômicos (NAFTA, UE, ÁSIA, MERCOSUL), aos quais são transferidas algumas funções dos Estados Nacionais, revela a fragilidade tanto de medidas microeconômicas reguladas pelo mercado quanto de intervenções estatais isoladas, como demonstrou o fracasso das estatizações bancárias promovidas pelo primeiro governo Mitterrand na França (Gilpin, 1988; Altvater, 1995; Arrighi, 1996).

\section{Novas Formas de Organização do Setor Público: Mudanças na Natureza do TrabalHo}

O novo quadro de acirrada competição internacional, que levou à reestruturação produtiva da economia, com a tendência à redução dos tempos de projeto e fabricação de produtos, à substituição da mão-deobra pela crescente automação e à racionalização organizacional, que traz o enxugamento das estruturas empresariais, com políticas de abertura de mercados e de privatização, eis o que levou os Estados Concorrenciais a disputas para atrair investimentos, ao incentivo da desregulamentação de direitos trabalhistas, à flexibilização do contrato de trabalho e à aceleração de variadas práticas de subcontratação, como formas de diminuir os custos do trabalho (Lipietz, 1991; Kolko, 1988). Os cortes de benefícios sociais, que passaram a ser vistos como fatores de pressão sobre o déficit público, tornaram-se freqüentes, atingindo o Welfare State. Em 1986, por exemplo, 65\% dos desempregados nos EUA não recebiam nenhum seguro-desemprego (Kolko, 1988).

Problemas de antes da Segunda Guerra, como desemprego em massa, miséria, instabilidade social e política, que a golden age fordista tinha em grande parte eliminado nas economias centrais com a intervenção estatal de caráter keynesiano na economia, reapareceram depois de 1973. O desemprego na Europa Ocidental subiu de 1,5\% em média, nos anos 60, para 9,2\%, no final dos anos 80 (Hobsbawm, 1995). Entre 1980/86 o desemprego cresceu na OCDE, enquanto a produtividade crescia e os salários reais caíam. As altas taxas de desemprego em 1993 apontadas pela OIT (1994) confirmam um quadro de desemprego estrutural: 11,2\% no Canadá; $6,9 \%$ nos EUA; $2,5 \%$ no Japão; $8,9 \%$ na Alemanha; $11,7 \%$ na França; $10,2 \%$ na Itália; $10,3 \%$ no Reino Unido; 8,2\% na Suécia e 22,7\% na Espanha.

No Japão, onde 66\% das empresas são pequenas e médias, subcontratadas das conhecidas gigantes (Kolko, 1988), mesmo os cerca de 30\% de core workers, empregados das grandes empresas com salários e condições de trabalho melhores, foram atingidos. Principalmente a partir da drástica desvalorização do dólar em face do iene no início do governo Clinton, que ocasionou aumento dos custos de produção japoneses, houve 
grande transferência de unidades de produção para fora do Japão. A política de emprego vitalício foi atingida, a transferência de trabalhadores para níveis inferiores em empresas subcontratadas está aumentando e demissões têm ocorrido (Osawa apud Hirata, 1993).

Toda essa situação tem induzido forte polarização social nas sociedades mais desenvolvidas. Há número cada vez maior de trabalhadores divididos em empregos precários ou desempregados e um grupo cada vez menor e progressivamente desestabilizado de trabalhadores semiqualificados, em contraposição ao minúsculo grupo dos superqualificados (Lipietz, 1991; Kurz, 1992).

A mudança do trabalho de salários relativamente altos na indústria pesada para ocupações de baixos salários, com o emprego temporário e os empregos de tempo parcial aumentando, vem acompanhada de aumento expressivo de variadas práticas de subcontratação ou terceirização em todas as áreas da economia (Mattoso, 1995). O número de empregos de tempo parcial nos EUA cresceu 58\% entre 1980/88, e corresponde a 30\% dos empregos na indústria eletrônica do Silicon Valley, Califórnia (Kolko, 1988).

A natureza do trabalho está mudando. A forma de emprego tradicional, o trabalho em tempo integral por tempo indeterminado, nos setores industrial e de serviços reestruturados, está sendo substituída pelas várias formas de cost-free labor: trabalho temporário, por tempo determinado, em tempo parcial (part-time), em casa, aprendizes, estagiários (Kolko, 1988; Mattoso, 1995). As empresas estão reduzindo o tamanho da força de trabalho diretamente empregada, os core workers. O número de cost-free labor, pouco significativo no pós-Segunda Guerra, passou a crescer mais do que o emprego em tempo integral: entre 1983/89, por exemplo, o emprego em tempo parcial cresceu na OCDE a uma média anual de $2,1 \%$, contra $1,5 \%$ de crescimento do emprego por tempo integral (Mattoso, 1995).

Para o cost-free labor o empregador não tem custos com auxílio-doença, seguro-saúde, férias e benefícios, e os salários são usualmente $50 \%$ a $30 \%$ menores do que os salários dos core workers. O custo de pessoal não é mais custo fixo. Os trabalhadores temporários e também a subcontratação/terceirização têm-se tornado parte integrante do ajuste das empresas às mudanças cíclicas (Kolko, 1988). Esta mão-de-obra subcontratada pode ser composta de profissionais muito qualificados (marketing, informática etc) ou não qualificados (limpeza, transporte etc).

Com a concentração nos produtos/serviços da empresa (chamada de focalização) sobre os quais ela detém vantagens competitivas, gerando redes de empresas subcontratadas, abandonando os sistemas produtivos fordistas mais complexos e menos flexíveis, alcança-se maior agilidade e flexibilidade administrativa; maior possibilidade de controle de gestão da produção (e, no caso do setor público, menor ingerência política); maior facilidade na gestão da mão-de-obra (Savas, 1987). A redução de custos é associada às práticas de subcontratação por diversos autores (Vickers e Yarrow, 1988; Martins, 1994). Outro efeito é o aumento do número de micro e pequenas empresas em todos os setores da economia (Martins, 1994).

A terceirização via subcontratação de empresas privadas é a solução mais citada numa extensa pesquisa feita por Savas (1987), secretário do governo Reagan, sobre privatização de serviços públicos em 1780 municípios dos EUA: transporte, saúde, lazer, e demais serviços de apoio, até patrulhamento de ruas e administração de recursos humanos. $\mathrm{O}$ autor conclui que há economia em custos de maneira geral, além dos pontos citados no parágrafo acima.

A partir de 1979, com a ascensão da corrente liberal ao governo britânico, os municípios e órgãos públicos federais foram incentivados a contratar prestadores de serviços privados, terceirizando a coleta de lixo, a limpeza de ruas, a limpeza e manutenção de hospitais e a manutenção de obras e prédios públicos. Segundo Vickers e Yarrow (1988), os servidores públicos, que antes se beneficiavam da posição de monopólio, foram colocados frente a frente com a competição do setor privado, e a evidência dos números e dados mostra importantes ganhos em diminuição de custos. Houve demissão de $37,2 \%$ dos servidores públicos empregados na coleta de lixo e limpeza de ruas no Reino Unido, $25 \%$ em média de queda nos níveis salariais, férias menores e ausência de seguridade social (Labour, 1987).

O monitoramento por parte do Estado (Vickers e Yarrow, 1988) pode ser dificultado devido à complexidade de um contrato de concessão de determinado serviço público, tornando-se necessária uma continuada relação contratual, o que envolve contínuos custos adicionais ( 10 a 15\%, segundo estudos feitos no Reino Unido). A 
ruptura de contrato devido ao descumprimento das obrigações pela subcontratada cria dificuldades para o Estado providenciar imediata substituição e continuidade dos serviços. Esta limitação na flexibilidade do governo para lidar com emergências devido à subcontratação é criticada também nos EUA (Savas, 1987).

Segundo Mattoso (1995), é amplamente reconhecido que os trabalhadores cujos contratos de trabalho foram flexibilizados dentro da OCDE tiveram salários rebaixados e o acesso à seguridade social e assistência médica restringido ou eliminado. Apesar das diferenças nacionais, o mercado de trabalho sob a égide fordista fragmentou-se e se desestruturou.

Se em 1991 40\% do emprego no Reino Unido já era constituído pela mão-de-obra contratada temporariamente e subcontratada, a maioria excluída do sistema de benefícios sociais (Mattoso, 1995), podese imaginar a dimensão social dos impactos que estes processos estão trazendo ao mercado de trabalho brasileiro, cujo perfil já é de acentuada heterogeneidade e onde o trabalhador jamais gozou de proteção social sequer comparável à existente nas economias centrais.

Os sindicatos nos países mais desenvolvidos, pressionados pelo desemprego, pelas ameaças de falências e fusões, com seu poder de pressão reduzido, reconheceram a fragmentação da força de trabalho e fizeram concessões salariais e em benefícios (Kolko, 1988). Devido à menor concentração de trabalhadores nessas empresas subcontratadas, que são menores, os empregadores procuram ganhar maior controle do conflito nas relações de trabalho (Leite, 1994).

As práticas de subcontratação têm-se difundido com rapidez no Brasil, segundo pesquisa feita pelo DIEESE (Leite, 1994). Como indica levantamento da Coopers \& Librand com 87 grandes empresas brasileiras (out/ 1994), a terceirização se dá prioritariamente em áreas de apoio (limpeza, alimentação, segurança etc); mas pesquisas recentes têm indicado aumento na subcontratação da produção ou da prestação direta de serviços (Leite, 1994). A subcontratação é mais generalizada em setores de ponta da economia. Essa tendência se acentuou no Brasil primeiramente na região do $\mathrm{ABCD}$ paulista.

Segundo pesquisa realizada pelo DIEESE (1994), a terceirização no Brasil acompanha a tendência internacional, estando, via de regra, associada a: diminuição de custos; aumento do número de micro/pequenas empresas; enxugamento de estruturas organizacionais, ocasionando demissões; menores salários; perdas de benefícios e vantagens salariais constantes dos acordos coletivos sindicais; precarização dos vínculos empregatícios, das condições de trabalho e de segurança; crescimento do trabalho temporário.

\section{Consideraçóes Metodológicas}

A escolha do setor de telecomunicações se justifica pelo fato de este ser um dos setores de ponta na economia e pela sua importância estratégica (Kolko, 1988).

A junção das telecomunicações com a informática, chamada de telemática, não só está mudando a natureza dos produtos e processos, como está viabilizando novas configurações interfirmas. A importância crescente e vital da infra-estrutura de telemática para a determinação da competitividade empresarial é apontada e exemplificada por vários autores no âmbito da OCDE (Tauile et al., 1994).

Como objeto de pesquisa definiu-se o setor responsável pela prestação e operação dos serviços de telecomunicações no Brasil. A estratégia metodológica adotada para escolha das empresas definiu duas operadoras de porte dentro do Sistema Telebrás. A escolha recaiu sobre a Telecomunicações de Minas Gerais - TELEMIG, e a Telecomunicações do Rio de Janeiro - TELERJ, como as empresas do estudo.

A TELERJ e a TELEMIG são a terceira e a quarta colocadas, respectivamente, entre as 31 operadoras dos serviços de telecomunicações do país em relação à receita, patrimônio líquido e número de trabalhadores.

As técnicas de pesquisa utilizadas foram entrevistas semi-estruturadas e análise documental.

Foram entrevistados gerentes das duas empresas pesquisadas responsáveis pelo gerenciamento dos contratos e pela fiscalização dos serviços contratados. Foram feitas entrevistas com dirigentes dos sindicatos de 
trabalhadores em telecomunicações dos dois Estados.

Dados foram fornecidos pelas empresas e cruzados com os dados fornecidos pelos sindicatos. Procedeuse à análise de relatórios anuais e de avaliação de desempenho das administrações das empresas, de circulares internas das empresas, de pautas de reivindicações dos sindicatos, de atas e relatórios de reuniões, seminários e debates sindicais sobre a questão, de jornais e demais publicações sindicais.

Os termos subcontratação e terceirização são equivalentes. Há autores que preferem designar como terceirização todo o trabalho/serviço feito por terceiros; daí a origem do termo. Já o termo subcontratação pode também ser usado no sentido mais genérico para representar todo o trabalho/serviço feito por outras empresas, estando a origem do termo na expressão de língua inglesa contracting out. No decorrer desse artigo o autor utiliza preferencialmente o termo subcontratação, por entender que este dá uma idéia mais exata do fenômeno, utilizando o termo terceirização mais como recurso de estilo para evitar muita repetição tediosa.

O período pesquisado retrata a situação em março/abril de 1996, procurando-se recuar no tempo de maneira a que se possibilite a compreensão de todo o processo.

\section{ANálise dos Resultados}

Inicialmente adotado nos anos 70 para atender à demanda crescente pelos serviços de telecomunicações, quando praticamente os únicos serviços subcontratados eram relativos à expansão/implantação de novas redes de telecomunicações, o processo de terceirização começou a se estender na década seguinte para os setores de manutenção de redes existentes e apoio (limpeza, alimentação, restaurante e vigilância), em parte como estratégia para contornar a proibição governamental de aumento do quadro de pessoal próprio (core workers). A partir de meados dos anos 80 , a contratação de trabalhadores temporários (telefonistas, por exemplo) cresceu e completou-se a terceirização do restante dos serviços de apoio (recepção, infra-estrutura predial, transporte etc).

Nos anos 90 a contratação de temporários e a terceirização se generalizaram para praticamente todas as funções exercidas nas empresas, passando a ser incorporadas pela administração como estratégia organizacional permanente, até para minorar os impactos das constantes inovações tecnológicas sobre os core workers, como no caso das telefonistas (Carvalho Neto, 1995).

Outro fator que também tem impulsionado a contratação temporária a partir de 1993, segundo os gerentes entrevistados, é a morosidade dos processos de admissão de pessoal mediante concursos públicos, que passaram a ser obrigatórios depois de prolongada campanha sindical pela transparência na gestão das empresas estatais. Os trâmites burocráticos retardariam a contratação de core workers necessários, pelo que as empresas acabam contratando trabalhadores temporários.

Um problema que ocorre com a contratação temporária, freqüentemente levantado pelos gerentes, é que o trabalhador tem de ser demitido e trocado por outro justamente quando finaliza o seu treinamento on the job, o que se dá geralmente ao final dos 135 dias permitidos pela legislação.

Os dados analisados e as respostas das entrevistas feitas tanto com gerentes quanto com sindicalistas indicam que hoje todas as funções exercidas nas empresas pesquisadas podem ser terceirizadas, umas totalmente, como as ligadas à limpeza, à alimentação e infra-estrutura; outras em parte, como instaladores/ reparadores de linhas de assinantes, pessoal de manutenção de rede, manutenção de centrais, e outras ainda mais qualificadas, como engenheiros de projetos/manutenção e analistas de sistemas. Em suma, qualquer atividade, qualificada ou não, excluindo diretores e gerentes, pode ser terceirizada total, parcial ou residualmente, de forma ocasional, sazonal ou permanente.

Em Minas Gerais o número total de trabalhadores subcontratados ultrapassa em muito o número de core workers. Essa imensa periferia é de aproximadamente 12.000 trabalhadores, 56,53\% maior do que os 7.666 core workers (março/1996), ou seja, mais de uma vez e meia o número de pessoal próprio da empresa pública contratante. Enquanto o número de trabalhadores subcontratados aumentou, o número dos core workers apresentou até ligeiro declínio nos últimos 9 anos (queda de 4,67\% entre 1987/95). 
Os salários pagos a funções equivalentes são em geral menores nas empresas subcontratadas (por exemplo, um emendador de cabos telefônicos ganha menos da metade ao exercer a mesma função numa subcontratada). As condições de trabalho são em geral assaz inferiores nas subcontratadas (infra-estrutura, segurança, saúde e higiene), bem como o sistema de concessão de benefícios, este praticamente inexistente. As empresas maiores e mais organizadas, especialmente as prestadoras de serviços técnicos, geralmente apresentam menor índice de precarização do contrato e das condições de trabalho do que as empresas prestadoras de serviços de apoio e locadoras de mão-de-obra temporária.

A terceirização nas empresas pesquisadas é feita por empresas que prestam tanto serviços técnicos externos (implantação de redes de telecomunicações, por exemplo), como serviços técnicos de caráter interno/externo (manutencão de rede), algumas vezes os mesmos serviços que são prestados também pelos core workers. Os serviços de apoio como cópias e impressões, correspondência, microfilmagem, limpeza, alimentação, manutenção de veículos, vigilância, recepção, infra-estrutura predial (bombeiros, eletricistas, pintura) etc, são totalmente terceirizados, prestados permanentemente por empresas contratadas que atuam no interior das empresas contratantes pesquisadas. Além disso, os trabalhadores temporários que trabalham no interior das empresas, dividindo o espaço com os core workers, muitas vezes com as mesmas funções (como no caso das telefonistas), são subcontratados de empresas locadoras de mão-de-obra.

A subcontratação na área de serviços públicos de telecomunicações nas empresas do estudo possibilitou o surgimento de inúmeras pequenas e médias empresas e, em menor número, de empresas de porte que atuam também no exterior.

Tanto os gerentes quanto os sindicalistas entrevistados se mostraram de alguma forma e em variados graus informados sobre as tendências internacionais de focalização e subcontratação, de flexibilização do contrato de trabalho e, em alguns casos, sobre a reestruturação produtiva internacional em curso.

As empresas públicas pesquisadas fazem o contrato para determinada obra ou para prestação de determinado serviço em homens/hora. No caso de prestação de serviços os contratos têm geralmente vigência de um ano, depois há nova licitação. A lei de licitações número 8.666 só estabelece que o menor preço deve vencer, não fazendo qualquer menção à qualidade, talvez para não deixar margem à subjetividade que a questão da qualidade carrega. Mas isso causa problemas à administração do setor público contratante, já que a proposta de menor preço não é necessariamente aquela de maior qualidade, e à gerência do contrato só resta, no caso de má prestação do serviço por parte da subcontratada, quando consegue, cancelar o contrato depois de iniciado, o que atrasa o processo. Vários exemplos desse tipo de problema foram fornecidos por gerentes entrevistados.

A modalidade contratual denominada procite constitui uma das formas mais inusitadas de subcontratação que se revelam. O setor público fica à margem do processo, no qual uma prefeitura escolhe (sem necessidade de licitação) a empresa subcontratada, que se encarrega tanto da construção de toda a rede de telecomunicações, incluindo centrais, como da venda direta de linhas telefônicas aos usuários. As empresas públicas fornecem as especificações técnicas e incorporam a planta construída no final do processo, passando a ser responsáveis pela operação. A grande vantagem deste tipo de contrato é o custo zero para o Estado. No entanto a sua difusão tem sido impedida devido ao surgimento de vários problemas. Para exemplificar, em um município de Minas Gerais, a empresa subcontratada não conseguiu arrecadar recursos suficientes com a venda antecipada aos usuários, faliu e quem já havia comprado teve que aguardar 4 anos para ter seu telefone instalado, já que o Estado não tinha poder para interferir. Neste caso, a ausência do Estado como regulador acabou por prejudicar os cidadãos. Problemas técnicos que ficam para o setor público resolver e casos de corrupção, que envolvem prefeituras e empresas subcontratadas sem que as empresas públicas possam intervir, são outros problemas decorrentes desse tipo de contrato apontado pelos entrevistados.

A modalidade de subcontratação denominada turn key consiste na terceirização da expansão da rede de telecomunicações desde o projeto, passando pelas obras civis, pela construção de centrais de comutação, de transmissão e da rede de cabos, até instalar o telefone na residência do usuário. Anteriormente as empresas prestadoras de serviços públicos de telecomunicações subcontratavam cada uma destas diferentes e complexas partes em separado. Recentemente passou-se a contratar uma empresa de engenharia, que por sua vez subcontrata uma rede de empresas especializadas em cada tipo de serviço, no que se poderia chamar de “consórcio de especialização flexível". O setor público passa, assim, a terceirizar a própria administração dos diversos contratos, num movimento de aprofundamento e alargamento das práticas de subcontratação. 
No tocante aos processos de subcontratação em geral, denúncias de corrupção (que afetariam os custos) feitas pelos sindicatos, não são raras. Os sindicatos encontram na presença de ex-diretores e ex-funcionários graduados das contratantes na direção das subcontratadas indícios de favorecimento. Também no caso da iniciativa privada há esse tipo de denúncias, segundo o DIEESE (1994). Os sindicatos britânicos, em face da presença de ex-ministros e parlamentares governistas como consultores pagos ou diretores das subcontratadas também veêm indícios de favorecimento (Labour, 1987). Essas denúncias são feitas igualmente pelos críticos dos processos de subcontratação nos EUA. Savas (1987), embora aceitando a tese de que os processos de subcontratação são suscetíveis de corrupção, alega que corrupção também existe sob outras formas, quando o serviço é prestado sob o molde de monopólio estatal.

A intervenção sindical organizada tornou-se muito mais difícil depois que o processo de subcontratações ganhou peso, devido à divisão dos trabalhadores entre diferentes empresas e diferentes bases sindicais. Os core workers em telecomunicações estão organizados em um único sindicato e trabalham para duas e três empresas, no Rio de Janeiro e em Minas Gerais, respectivamente, facilitando a organização sindical e, conseqüentemente, conquistando melhores salários e benefícios (plano de saúde, auxílio-creche etc). Os trabalhadores subcontratados (para facilitar a compreensão, engloba-se nessa categoria os empregados temporários e os de empresas de prestação de serviços), por outro lado, são representados por vários sindicatos (de vigilantes, asseio e conservação, cabineiros/elevadores, oficiais eletricistas etc). Isso ocorre devido ao monopólio da representação sindical classificada pela profissão e outorgada pelo Ministério do Trabalho na era do corporativismo varguista e ao mecanismo do imposto sindical, vigentes até hoje, independente da vontade dos trabalhadores, que ainda não podem escolher seu sindicato livremente no Brasil, que ratificou a Convenção 87 da OIT sobre liberdade e autonomia sindical na década de 40, e até hoje não a adequou à legislação. Essa pulverização da representação sindical e as dificuldades colocadas pela arcaica estrutura sindical brasileira têm obstado, entre outros fatores, aos esforços dos sindicatos dos core workers em telecomunicações para representar os trabalhadores subcontratados, que invariavelmente têm salários rebaixados, benefícios perdidos e condições de segurança, de saúde e trabalho precarizadas, quando o serviço é terceirizado, e/ou comparativamente aos core workers.

Esse movimento de aumento do número de trabalhadores subcontratados, que recebem menores salários, com relações contratuais, com condições de trabalho e segurança mais precários, em contraposição à diminuição do núcleo de trabalhadores mais bem remunerados, que gozam de relativa estabilidade no emprego e melhores condições de trabalho e benefícios, vem ao encontro da tendência internacional encontrada na literatura.

\section{CONCLUSÓES}

As empresas pesquisadas têm experiência anterior em subcontratação de serviços públicos, mas esta prática, aliada à contratação temporária de trabalhadores, só se generalizou a partir dos anos 80 , intensificando-se nos anos 90, tomando corpo como estratégia gerencial.

O setor público de prestação de serviços de telecomunicações está subcontratando não só nas áreas de apoio, mas em todas as áreas, confirmando a tendência, recente no Brasil, de nova forma de organização do setor público apontada pela literatura. A prática da subcontratação avançou tanto nas empresas do estudo que se pode concluir isto: o setor público já experimenta o que se poderia chamar de quarteirização, ou seja, uma empresa subcontratada por sua vez subcontrata várias empresas especializadas em diferentes partes de um único grande projeto e gerencia esse consórcio, ficando responsável por todos os aspectos diante do setor público contratante que, assim, terceiriza boa parte da própria administração do contrato.

Outra forma ainda mais inusitada de subcontratação dos serviços públicos de telecomunicações encontrada pela pesquisa, embora não esteja sendo difundida devido aos vários problemas já citados, mostra a disposição do Estado de praticamente se retirar, enquanto poder regulatório de fato, da relação entre as prefeituras e as empresas subcontratadas.

Os ganhos na diminuição de custos e em flexibilidade gerencial e operacional parecem confirmar-se, em consonância com a literatura, em que pesem as dificuldades no monitoramento das empresas subcontratadas similares às apontadas por Vickers e Yarrow (1988) no Reino Unido e os entraves à qualidade trazidos 
pela legislação de licitações no Brasil.

A terceirização de serviços públicos de telecomunicações nas empresas pesquisadas possibilitou o surgimento não só de grande número de pequenas e médias empresas, como salientam Savas (1987) e Martins (1994), mas também de algumas empresas de porte que já atuam no mercado internacional.

A pesquisa confirma a tendência atual da grande corporação moderna, apontada por diversos autores (Mattoso, 1995; Martins, 1994; Lipietz, 1991), de empregar pequeno núcleo básico, e cada vez menor, de core workers e subcontratar uma massa de pequenas e médias empresas. A extensa periferia de trabalhadores temporários e subcontratados chegou a suplantar em mais de uma vez e meia o número de core workers no setor público de telecomunicações pesquisado. Mesmo no núcleo, os core, cujo número apresenta ligeiro declínio nos últimos 9 anos, não mais gozariam da relativa estabilidade no emprego com que contavam, tendo havido contratação de trabalhadores temporários também aí.

A pesquisa mostrou que as novas formas de organização que introduziram o trabalho temporário e a subcontratação na prestação de serviços públicos de telecomunicações, consonante o que está ocorrendo nos países mais desenvolvidos economicamente, provocaram mudanças na natureza do trabalho. Hoje há duas categorias distintas de trabalhadores em telecomunicações: os trabalhadores subcontratados e os core workers, os trabalhadores pertencentes ao quadro de pessoal das empresas de telecomunicações pesquisadas.

Os core workers, em inúmeros casos levantados na pesquisa, executam as mesmas tarefas que os trabalhadores subcontratados e ganham salários duas ou mais vezes maiores, mais benefícios e melhores condições de trabalho, de saúde e segurança. Geralmente, os core workers executam tarefas que exigem maior qualificação, mas mesmo essas tarefas têm sido terceirizadas, de forma permanente, sazonal ou parcial.

Os resultados encontrados indicam que os efeitos da subcontratação de trabalhadores temporários e de serviços públicos de telecomunicações nas relações de trabalho apresentam características similares àquelas que ocorrem na iniciativa privada. A subcontratação nas empresas pesquisadas contribuiu para a precarização da relação contratual, dos salários e das condições de trabalho, expressando a atual tendência internacional de flexibilização do mercado de trabalho e de maior informalização da economia, que já atingecerca de metade da população economicamente ativa no Brasil (Demo, 1994).

Os sindicatos brasileiros, numa economia com elevado grau de informalização e uma das piores taxas de concentração de renda do mundo, quase sempre tiveram de enfrentar a ameaça de ampla reserva de mãode-obra. Com a divisão dos trabalhadores entre várias empresas subcontratadas, os sindicatos têm sua ação extremamente dificultada. O quadro fica ainda mais crítico com as dificuldades de mobilização de uma categoria fragmentada entre núcleo cada vez menor de core workers permanentemente ameaçados de perderem seus empregos para uma periferia cada vez maior de trabalhadores subcontratados.

A pesquisa foi feita em empresas onde há sindicatos organizados e bastante atuantes, há 15 e 12 anos (Minas Gerais e Rio de Janeiro, respectivamente). Relatos dos sindicalistas entrevistados e exame de extensa documentação indicam grande dificuldade de organização sindical, o que coaduna com pesquisa feita pelo DIEESE (1994) e com a literatura (Labour, 1987;Kolko, 1988; Martins, 1994; Mattoso, 1995).

O acordo assinado entre a Comissão de Fábrica e a direção da Volksvagen em São Bernardo do Campo (SP), garantindo negociação da empresa com o sindicato no caso de terceirização é bastante relevante, embora raro (DIEESE, 1994).Esse pode ser um dos caminhos para que as práticas de subcontratação se dêem dentro do espírito de efetiva modernização industrial, como parte de alternativas concretas e mais abrangentes em termos de política industrial.

A ampliação da subcontratação, do emprego part-time e de outras formas de trabalho como o domiciliar, não deveria ser considerada necessariamente negativa, como salienta Mattoso (1995), desde que fosse resultante de compromisso social mais abrangente de redivisão do trabalho disponível na sociedade, com acesso à seguridade social.

\section{ReferénCias Bibliográficas}




\section{ALTVATER, E.}

O mercado mundial como área de operações ou a transformação do Estado Nacional Soberano no Estado Nacional Concorrencial. Revista Indicadores Econômicos, v.23, n.1, maio 1995.

\section{ARRIGHI, G.}

O longo século XX.: dinheiro, poder e as origens do nosso tempo. Rio de Janeiro: Contraponto/ UNESP, 1996.

CARVALHO NETO, A. M.

Inovações tecnológicas no setor de telecomunicações e o impacto sobre o trabalho. Belo Horizonte, 1995. Dissertação de Mestrado - Centro de Pós-Graduação e Pesquisa em Administração/Universidade Federal de Minas Gerais.

Privatização e eficiência organiza-cional: a experiência britânica e os reflexos sobre o processo brasileiro. In: XVIII Encontro Anual da ANPAD, 1994, Curitiba. Anais ... Curitiba: ANPAD, 1994, v.3.

DEMO, P.

O futuro do trabalhador do futuro. Brasília: OIT, 1994.

DIEESE.

Trabalho e reestruturação produtiva. São Paulo: Parma, 1994.

GILPIN, R.

The political economy of international relations. New Jersey: Princeton University Press, 1987.

HIRATA, $\mathrm{H}$.

Sobre o modelo japonês. São Paulo: EDUSP, 1993.

HOBSBAWM, E.

Era dos extremos. Rio de Janeiro: Companhia das Letras, 1995.

KOLKO, J.

Restructuring the world economy. New York: Pantheon Books, 1988.

KURZ, R.

O colapso da modernização. Rio de Janeiro: Paz e Terra, 1992.

KURTZMAN, J.

A morte do dinheiro: como a economia eletrônica desestabilizou os mercados mundiais e criou o caos financeiro. São Paulo: Atlas, 1994.

\section{LABOUR RESEARCH DEPARTMENT.}

Privatisation - paying the price.

Londres: 1987.

LEITE, M. de P.

O mundo do trabalho. Campinas: Página Aberta, 1994.

LIPIETZ, A.

Audácia: uma alternativa para o século XXI. São Paulo: Nobel, 1991.

MARTINS, H. H. T. de S.

In: MARTINS, H. H. T. de S., RAMALHO, J. R. (orgs.). Terceirização: diversidade e negociação no mundo do trabalho. São Paulo: HUCITEC/CEDI- NETS, 1994. 
MATTOSO, J.

A desordem do trabalho. São Paulo: Página Aberta, 1995.

OIT.

El trabajo en el mundo: la situación mundial del empleo. Genebra: 1994.

PORTER, M. E.

A vantagem competitiva das nações. Rio de Janeiro: Campus, 1993.

SAVAS, E. S.

Privatização: a chave para um governo melhor. Rio de Janeiro: $\quad$ Nordica, 1987.

TAUILE, J. R. et al.

Telecomunicações: mudança tecnológica e suas implicações econômicas, sociais e institucionais. Rio de Janeiro: Instituto de Economia Industrial da UFRJ/Convênio EMBRATEL, Relatório Final, 1994.

TAVARES, M. C.,

FIORI, J. L.

Desajuste global e modernização conservadora. Rio de Janeiro: Paz e Terra, 1993.

TEIXEIRA, A.

O ajuste impossível: um estudo sobre a desestruturação da ordem econômica mundial e seu impacto sobre o Brasil. Rio de Janeiro: Editora

da UFRJ, 1994.

VICKERS, J.,

YARROW, G.

Privatization - an economic analysis. Cambridge: MIT Press, 1988. 